\title{
Stage III Breast Cancer AJCC v7
}

National Cancer Institute

\section{Source}

National Cancer Institute. Stage III Breast Cancer A/CC v7. NCI Thesaurus. Code C88376.

Stage III includes: IIIA : (T0, N2, M0); (T1, N2, M0); (T2, N2, M0); (T3, N1, M0); (T3, N2, M0), IIIB: (T4, N0, M0); (T4, N1, M0); (T4, N2, M0), and IIIC: (any T, N3, M0). T4: Tumor of any size with direct extension to the chest wall and/or to the skin (ulceration or skin nodules). N2: Metastases in ipsilateral level I, II axillary lymph nodes that are clinically fixed or matted; or in clinically detected ipsilateral internal mammary nodes in the absence of clinically evident axillary lymph node metastases. N3: Metastases in ipsilateral infraclavicular (level III) axillary lymph nodes(s) with or without level I, II axillary lymph node involvement; or in clinically detected ipsilateral internal mammary lymph node(s) with clinically evident level I, II axillary lymph node metastases; or metastases in ipsilateral supraclavicular lymph node(s) with or without axillary or internal mammary lymph node involvement. M0: No clinical or radiographic evidence of distant metastasis. M0 includes $\mathrm{MO}(\mathrm{i}+)$. (AJCC 7th Ed.) 